\title{
Movimento Escola sem Partido: os sentidos nos discursos sobre a
}

\section{esquerda}

\author{
Movimiento Escola sem Partido: los sentidos en los discursos sobre la \\ izquierda
}

Movement Escola sem Partido: the senses in the speeches about the left

\author{
Rocheli Regina Predebon Silveira1
}

\begin{abstract}
Resumo
Os discursos a partir do ambiente digital foram ressignificados, assim como os sujeitos e sentidos passaram a ter uma nova constituição. Com isso, esse trabalho busca compreender os sentidos que podemos estabelecer a partir do termo "esquerda", empregado nos discursos dos seguidores do movimento Escola sem Partido em sua página oficial no Facebook. Para tentar estabelecer esses sentidos, nos embasamos na teoria da Análise de Discurso de linha francesa, mobilizando principalmente os conceitos sobre discurso, acontecimento e memória digital, além do conceito de máquina ideológica. A partir da análise percebemos que as formações discursivas (FDs) em torno do termo "esquerda" vêm sempre imbuídas de negatividade e associadas a algo ruim. O que implica em um assujeitamento dos sujeitos inscritos nessas FDs por estarem sendo afetados por uma instituição que funciona como uma "máquina ideológica", aqui posta como o movimento ESP.
\end{abstract}

Palavras-chave: Discurso digital. Sentidos. Esquerda. Movimento Escola sem Partido.

\section{Resumen}

Los discursos a partir del ambiente digital fueron resignificados, así como los sujetos y sentidos pasaron a tener una nueva constitución. Con esto, eso trabajo busca compreender los sentidos que podemos establecer a partir del termo "izquierda", empleado en los discursos de los seguidores del movimiento Escola sem Partido en su página ofíciale del Facebook. Para intentar establecer esos sentidos, nos basamos en la teoría de la Análisis de Discurso de línea francesa, movilizando principalmente los conceptos sobre el discurso, acontecimiento y memoria digital, además de lo concepto de memoria máquina ideológica. A partir del análisis percibimos que las formaciones discursivas (FDs) en torno del termo "izquierda" viene siempre imbuidas de negatividad y asociadas a algo ruin. El que implica en un asujetamiento de los sujetos inscritos en esas FDs por estén siendo afectados por una institución que funciona como una "máquina ideológica", aquí puesta como el movimiento ESP.

Palabras-clave: Discurso digital. Sentidos. Izquierda. Movimiento Escola sem Partido.

\begin{abstract}
The discourses from the digital environment were re-signified, just as the subjects and the senses began to have a new constitution.With this, this work seeks to understand the meanings we can establish from the term "left", used in the speeches of the followers of the movement Escola Sem Partido in its official Facebook page. In order to try to establish these meanings, we are based on the theory of Discourse Analysis of French line, mobilizing mainly the concepts on speech, event and digital memory, besides the concept of ideological machine. From the analysis we see that the discursive formations (FDs) around the term "left" always imbued with negativity and associated with something bad. This implies a problem of the subjects enrolled in these FDs because they are being affected by an institution that functions as an "ideological machine", here referred to as the ESP movement.
\end{abstract}

\footnotetext{
${ }^{1}$ Mestranda pelo Programa de Pós-Graduação em Letras da Universidade Federal de Santa Maria. Bolsista CAPES.
} 
KEYWORDS: Digital speech. Senses. Left. Movement Escola Sem Partido

\section{Introdução}

As redes sociais se caracterizam por ser um espaço onde os sujeitos se sentem a vontade para expor o que estão pensando, bem como, para opinar sobre os mais diversos assuntos, como se todos fossem "especialistas" naquilo que estão falando, ou até julgando. Isso encadeou uma mudança na discursividade, não só nas redes sociais, mas no digital como um todo, Cristiane Dias nos aponta que,

\footnotetext{
O digital produziu uma mudança na discursividade do mundo, [...] nas relações históricas, sociais e ideológicas, na constituição dos sujeitos e dos sentidos, mas também na forma dos relacionamentos, do trabalho, da mobilidade, dos encontros, até mesmo do fazer científico, do qual faz parte a maneira de sua produção e seus meios de circulação. (DIAS, 2016, p.9).
}

Como percebemos, através do digital, as relações foram ressignificadas e, por consequência, os sujeitos e os sentidos também têm uma nova forma de constituição. Quanto ao sentido, podemos entender através de Orlandi (1996), que muitos são os sentidos que podem ser estabelecidos, a partir do discurso, já que, como a autora sugere, os discursos podem partir para várias direções e assim, significar de maneiras distintas, levando em consideração a historicidade e a ideologia de quem está a interpretá-los. Aqui, no caso, pensando no meio digital, as redes sociais, levando em conta as mudanças ocorridas nas relações da historicidade e da ideologia, os sentidos podem ser múltiplos.

Partindo disso, esse trabalho tem como objetivo compreender os sentidos que podemos estabelecer a partir do termo "esquerda", empregado nos discursos dos seguidores do movimento Escola sem Partido (ESP) em sua página oficial no Facebook. Importa mencionar que os termos a serem analisados foram retirados de comentários em postagens sobre professores, para o movimento, "doutrinadores", como por exemplo: "Pra mim, a pior doutrinação ideológica é aquela feita de forma implícita, omitindo livros, alterando o contexto dos livros, sugerindo a adoção de uma bibliografia tendenciosa, etc. Esta sim é uma forma mais perniciosa que a Esquerda utilizar na doutrinação de jovens e adolescentes nas escolas e universidades."

A partir disso, para tentar estabelecer sentidos ao termo "esquerda", primeiramente entenderemos como se dá o discurso no meio digital. Vamos, em seguida, compreender o gesto de interpretação proposto por Eni Orlandi (1996). Percorreremos um breve histórico 
sobre o movimento Escola sem Partido, para, só então, estabelecermos os principais sentidos interpretados nas sequências discursivas escolhidas para análise.

É importante ressaltar que, esse movimento de interpretação, se torna necessário, na medida em que o ESP vem ganhando cada vez mais seguidores e apoiadores que simpatizam com as ideias defendidas por esse grupo. Com isso, a cada dia, temos inúmeras postagens e comentários na página do Facebook do movimento, postagens que tem grande repercussão, atingindo milhares de internautas, seguidores ou não do ESP.

\section{Do Discurso ao Digital}

Na Análise de Discurso (AD) de linha francesa, o social e o histórico estão intimamente relacionados, não podendo ser dissociados, por isso, na $\mathrm{AD}$ o discurso é definido como "efeitos de sentidos entre locutores", conforme Orlandi (2006). Desse modo, os sentidos podem mudar de acordo com a posição que o locutor, ou melhor dizendo, de acordo com a posição que o sujeito toma. Os efeitos de sentidos, então, se dão nessas relações de sentidos entre sujeitos ideologicamente afetados.

No ambiente digital, os sentidos, segundo Cristiane Dias (2016), possuem uma nova forma de constituição, isso porque as formas de relacionamento com a família, amigos, afetos, enfim, as relações com os sujeitos são ressignificadas. Dessa forma, a autora acredita que nessas “[...] relações sociais, há derivas para outros lugares de significação, que produzem novos sentidos no jogo entre o mesmo e o diferente." (DIAS, 2016, p. 09). Os sentidos, então, podem ser estabelecidos em diversas direções, tendo múltiplos significados, como observado em Orlandi (1996), “Ele 'parte’ em inúmeras direções, em múltiplos planos de significantes. Diferentes versões de um texto, diferentes formulações constituem novos produtos significativos." (p. 14).

Ao introduzir esse trabalho, vimos que o meio digital provocou uma mudança na discursividade, o que gerou uma ressignificação da relação entre a história, o social e a ideologia na constituição do sujeito. Isso, segundo Dias (2016) é um desafio ao analista de discurso, na medida em que terá que observar essas mudanças e compreendê-las para que possa chegar à significação. Essa mudança na discursividade é chamada pela autora como digitalização do mundo, que seriam:

[...] práticas de linguagem que tendem à metaforização das relações sociais e das práticas dos sujeitos que, por meio do acesso deslocam o campo da 'luta' para uma inscrição na forma digital. Em outros termos, a digitalização do mundo é um processo de historicização dos sentidos que desloca o modo de significação, produzindo uma forma material outra, porque inscreve o dizer, o fazer, as práticas 
dos sujeitos, em outras condições de produção, afetada por outras instituições, como as corporações do tipo Google ou Microsoft, garantindo o funcionamento da máquina ideológica por meio das relações de poder e de produção-reprodução do trabalho. (DIAS, 2016, p.10-1)

Em nosso caso, podemos, além de perceber o Google ou a Microsoft como as instituições que funcionam como máquina ideológica, temos o Facebook e o próprio, e principalmente, movimento ESP funcionando como uma "máquina ideológica", já que, conforme Pêcheux (1997), a máquina ideológica não é apenas o lugar da classe dominante, mas também o lugar da transformação. Assim, o movimento ESP, além de se constituir na classe dominante é um lugar de transformação, portanto, é uma máquina ideológica. Máquina ideológica que afeta diariamente os seus seguidores e os "amigos" de seus seguidores, já que, um dos seus meios de divulgação, se não podemos dizer o seu maior meio de divulgação, é o Facebook, lugar onde com apenas um "clique" se alcança milhares e milhares de pessoas. Temos então diariamente, sujeitos sendo afetados por discursos que incitam a uma visão negativa sobre os partidos de esquerda, conforme veremos adiante.

Os sujeitos desse meio digital, segundo Dias (2016), possuem um "dizer repetidamente re-atualizado", ou seja, os dizeres estão sempre sendo repetidos. A autora chama isso de uma memória digital, em que os sujeitos se constituem, a partir do trabalho do interdiscurso que atualiza a todo momento os discursos, sempre levando em conta o acontecimento digital. Esse acontecimento digital é tão importante por conta da rapidez em que os discursos se materializam e, ao mesmo tempo, se dissolvem, se configurando novamente, já que, conforme Dias (Ibiden) nos aponta, os dizeres estão sempre se repetindo, se atualizando e re-atualizando. Quanto a memória no meio digital, Cristiane Dias parte do que Orlandi formula como memória metálica, para avançar e chegar ao que ela chama, então, de memória digital.

Para compreendermos a memória metálica é necessário distingui-la de outras duas noções: memória discursiva ou interdiscurso e memória institucional (arquivo). Segundo Orlandi (2006),

A memória discursiva ou interdiscurso (M. PÊCHEUX, 1975, J-J. COURTINE, 1981) é a que se constitui pelo esquecimento, na qual "fala uma voz sem nome". Aquela em que "algo fala antes, em outro lugar, independentemente" (M. PÊCHEUX,1975), produzindo o efeito do já-dito. Isto é, as nossas palavras trazem nelas outras palavras. Por outro lado, a memória institucional ou a que chamo a memória de arquivo ou simplesmente o arquivo, é aquela que não esquece, ou seja, a que as Instituições (Escola, Museu, eventos etc.) praticam, alimentam, normatizando o processo de significação, sustentando-o em uma textualidade documental, contribuindo na individualização dos sujeitos pelo Estado. E temos, enfim, a memória metálica, ou seja, a produzida pela mídia, pelas novas tecnologias de 
linguagem. A memória da máquina, da circulação, que não se produz pela historicidade, mas por um construto técnico (televisão, computador etc.). Sua particularidade é ser horizontal (e não vertical, como a define Courtine), não havendo assim estratificação em seu processo, mas distribuição em série, na forma de adição, acúmulo: o que foi dito aqui e ali e mais além vai-se juntando como se formasse uma rede de filiação e não apenas uma soma. Quantidade e não historicidade. (ORLANDI, 2006, p.05)

Ou seja, a memória discursiva é o já-dito, a de arquivo é a de normatização dos processos de significação instituídos pelas instituições. E a memória metálica, a memória tecnológica, se caracteriza por acumular já-ditos, não se produzindo na historicidade. Nesse sentido, Dias afirma que a memória digital vai além do funcionamento da memória metálica, “[...] pela quantidade, pela possibilidade de armazenamento e processamento de dados [...]" (DIAS, 2016, p. 12), se inscreve no funcionamento do digital, através do interdiscurso. Ou seja, a memória digital ao considerar o acontecimento digital, compreende pelo trabalho do interdiscurso, sempre uma atualização discursiva. Isso quer dizer que os discursos vão se acumulando já que a forma e a possibilidade de armazenamento é diferente e muito maior. Assim, percebemos, por exemplo, inúmeros comentários sendo proferidos sobre uma suposta má índole da esquerda, mesmo que já tenham sido ditos tantas outras vezes. Por isso, o gesto de interpretação nos ambientes digitais, deve considerar sempre esse acontecimento digital.

Para Orlandi (1996), o gesto de interpretação ocorre porque o discurso é marcado pela incompletude, através da relação com o silêncio ${ }^{2}$. Nessa perspectiva, a autora afirma que qualquer mudança na materialidade do texto, encadeia distintos gestos de interpretação, ou seja, “[...] diferentes posições do sujeito, com diferentes formações discursivas, distintos recortes de memória, distintas relações com a exterioridade.” (ORLANDI, 1996, p. 14), vão permitir diferentes gestos de interpretação. Se levarmos em conta, então, o acontecimento digital, teremos um gesto de interpretação distinto, já que as relações são diferentes.

Dessa forma, o discurso sobre à esquerda, neste trabalho pensado a partir da rede social Facebook, deve ser significado levando em conta essa memória que Cristiane Dias chama de memória digital. Isso porque as condições aqui de produção, não são quaisquer condições, mas sim uma que se dá no meio digital. Lugar em que os sujeitos estão sendo afetados pela "máquina ideológica”, aqui pensada, como o movimento ESP. E que, portanto,

\footnotetext{
${ }^{2}$ Silêncio aqui entendido, conforme nos aponta Orlandi (1997), como fundante, ou seja, o silêncio que "[...] atravessa as palavras, que existe entre elas, ou que indica que o sentido pode sempre ser outro, ou ainda que aquilo que o mais importante nunca se diz [...] (p. 14)". Isso quer dizer que o discurso é atravessado pelo silêncio. Conceito retirado do livro As formas do silêncio: no movimento dos sentidos, editora UNICAMP, $4^{\mathrm{a}}$ edição.
} 
o interdiscurso, funciona, a partir dessas relações de poder, postas pelo ESP. Lugar onde por conta do acontecimento digital, o gesto de interpretação será diferente.

\section{O movimento ESP}

O movimento Escola sem Partido (ESP), conforme sua página oficial na internet é uma iniciativa de pais e professores, que vem ganhando força por defender uma escola sem doutrinação política e ideológica. Criado em 2004, pelo advogado Miguel Nagib, segundo Penna $^{3}$, o movimento ganhou uma maior visibilidade a partir de 2008, quando a revista Veja em uma reportagem apontou o grupo como a "solução possível para o problema da doutrinação" (MOVIMENTO, 2015, p. 297); além disso, o movimento passou a apoiar um ensino sem as ideologias de gênero e, assim, ganhou um novo público de apoiadores.

Já em 2014, segundo Rodrigues ${ }^{4}$ (2016), o deputado estadual do Rio de Janeiro Flávio Bolsonaro buscou nos fundamentos do ESP as ideias para a criação de um projeto que regulamentaria o papel do professor em sala de aula. No ano seguinte foi a vez do deputado federal Izalci Ferreira propor uma emenda a LDB, propôs o "Programa Escola sem Partido", seguido do, também deputado federal, Rogério Marinho que inspirado no movimento, elaborou um projeto para criminalizar professores acusados de assediar ideologicamente alunos (RODRIGUES, 2016). No ano de 2017 foram inúmeros os projetos e propostas embasados no movimento ESP, que tramitaram nos legislativos federais, estaduais e municipais, alguns, inclusive, já aprovados.

O ESP ganha a cada dia mais apoiadores e simpatizantes. Para isso, o movimento conta com suas redes sociais, como os seus dois sites (programaescolasempartido.org e escolasempartido.org) e uma página no Facebook (Escola sem Partido), esses oficiais, fora os inúmeros não oficiais. Nesses sites são noticiados e debatidos assuntos em torno do tema central, o ESP. Os sites oficiais do movimento operam nas propagações de ideias do movimento.

Interessa-nos, nesse trabalho, a página oficial do movimento no Facebook, página que possui aproximadamente 160.000 (cento e sessenta mil) seguidores. Nela são feitas postagens de materiais preparados por professores com possíveis ideologias políticas, notícias sobre alunos que estão sendo, segundo a página, usados como "massa de manobra", ou ainda

\footnotetext{
${ }^{3}$ Fernando Penna é Doutor em Educação pela Universidade Federal do Rio de Janeiro e professor adjunto da Faculdade de Educação da Universidade Federal Fluminense. Estuda as manifestações reivindicatórias da comunidade conservadorista e reacionária, como o movimento Escola sem Partido.

${ }^{4} \mathrm{O}$ texto utilizado como referência nessa parte foi apresentado por Henrique Estrada Rodrigues, professor no Departamento de História da PUC-Rio, no dia 17 de junho de 2016 na "Fundação Casa de Rui Barbosa", onde ocorreu um debate sobre o movimento Escola Sem Partido.
} 
RELACult - Revista Latino-Americana de Estudos em Cultura e Sociedade

reportagens e artigos sobre o próprio grupo. Essas postagens repercutem vários compartilhamentos que atingem outros internautas, além de alcançar inúmeros comentários. São esses os comentários que nos interessam nesse trabalho, comentários especificamente de postagens referente a "doutrinação" dos professores.

\section{Os sentidos nos discursos sobre a esquerda}

A partir de nossa análise realizada nos comentários das postagens sobre os professores, para o movimento, doutrinadores, percebemos que haviam, além do termo esquerda, mais 3 (três) termos muito utilizados que se referiam aos professores como membros de partidos de esquerda, são eles: esquerdista, esquerdopata e esquedelhice. Nossa análise se deu em torno, então, desses 4 (quatro) termos e dos sentidos que eles incitam.

Para iniciar, tomemos as formações discursivas que se inscrevem na relação do termo esquerda com o comunismo, conforme podemos ver no seguinte exemplo:

Esses esquerdopatas infiltrados nas escolas e universidade são um perigo e precisam ser extirpados e varridos para o lixo da história. Cambada de comunistas safados.

Primeiramente, devemos entender que os sentidos negativos ligados ao comunismo vêm de muito tempo, conforme Mariani (1998), atrelado a um discurso anterior ao do Brasil, e que, através do jornalismo foi disseminado, também no Brasil. Uma primeira imagem que pode vir à memória, ao pensar em países com regimes comunistas é Cuba, que, segundo o veiculado pela mídia, é coberto de restrições e proibições. Dessa forma, se levamos em consideração que a mídia é a maior formadora de opiniões e como vimos é uma máquina ideológica, à esquerda ao ser relacionada ao comunismo, estaria tentando implementar um regime em que as pessoas teriam uma série de proibições e restrições e, por isso, são perigosos, como vimos na sequência discursiva acima. Ainda, quanto a isso, Indursky (2003) ressalta que o termo esquerda, sempre ressoa comunismo e com ele toda a "diabolização" que suscita, acrescentando que no comunismo os sentidos produzidos a partir desse termo giram em torno de inimigo. E, se são perigosos como vimos no exemplo acima, são inimigos. $\mathrm{Ou}$ então, são tão inimigos que podem ser considerados terroristas, ao serem comparados com os islamitas radicais, como vemos no próximo exemplo:

Jajá eles vão parar de doutrinar sobre os vermes comunistas, a agenda deles já estão virando para o islamismo. 
Nos exemplos a seguir, relacionado ao termo esquerdista, mais uma vez poderemos ver o sentido de inimigo atrelado a esquerda:

Um bando de jovens idiotizados pelos esquerdistas, que no futuro se arrependerão tarde demais por terem se prestado à este papel ridículo.

Analfabeto funcional ressentido. Até o presente momento não ouvi ninguém (ninguém mesmo) que é contra as reformas da previdência e trabalhista valer-se de argumentos plausíveis para justificar o posicionamento. Os argumentos (se é que se pode chamar de argumentos) são pífios e não contemplam os textos das reformas. Os detratores dessas reformas repetem apenas chavões esquerdistas (digo, dos movimentos sociais e sindicatos). Quando vejo isso, me vem à memória o porco Garganta, de A Revolução dos Bichos", de George Orwell, portavoz de Napoleão.

Nesses comentários, podemos perceber a relação que a esquerda possui com algo errado, ou ruim, pois só podemos nos arrepender de algo que fizemos se esse algo não é bom. Dessa forma, nos comentários na página do movimento ESP, ser de esquerda é ruim e errado, não deve ser seguido, porque quem seguir vai se arrepender. Além disso, percebemos que a imagem que se tem dos seguidores dos partidos de esquerda é de pessoas suscetíveis a não possuir opinião ou vontade própria e por isso, pessoas que são muito influenciáveis. No segundo exemplo, ao comentar sobre o porco Garganta, percebemos que o sujeito acredita que os professores, aqui visto como partidários de esquerda, são pessoas que possuem o poder de persuasão. Por isso são perigosos, e por isso, também, são inimigos, já que podem convencer outros sujeitos de seguir seus ideais.

No exemplo a seguir, ainda sobre o termo esquerdista, podemos ver junto a ele a palavra patota que tem por significado: "1 Fraude no jogo; batota. 2 Ação ardilosa para conduzir alguém ao erro; engano, logro" (MICHAELLIS, 2017).

UEM nao e aquela em que estao perseguindo uma prorfessora so pq ela nao é da patota esquerdista?

Nesse comentário, o sujeito acredita que os professores, por serem de esquerda, estão jogando sujo, através de suas ideologias, doutrinando os alunos e conduzindo eles ao erro.

Ainda, podemos perceber alguns sentidos que vêm imbricados junto aos sufixos na palavra esquerda, como esquerdopata e esquerdelhice. Termos que foram muito utilizados em comentários na página do movimento ESP. No primeiro termo, esquerdopata, inferimos a palavra psicopata junto. Psicopata, segundo o dicionário Michaelis (2017), significa alguém que sofre de doenças ou distúrbios mentais, isso quer dizer que quem é de esquerda tem 
problemas mentais é doente, e sujeitos nesse estado não são confiáveis. Nos discursos analisados ficou bem claro isso, como podemos ver no exemplo a seguir:

Essa educação problematizadora não recebe esse nome em vão! Infelizmente, tem sido um problema pela alienação desses esquerdopatas.

Para os seguidores do movimento ESP, os sujeitos de esquerda entram nas escolas para doutrinarem, para passarem apenas a sua verdade e não aceitam nada além disso, por isso, são psicopatas e são um problema, e por isso, assim como qualquer psicopata ou problema, devem ser banidos. Já que, no popular, utilizamos a palavra psicopata para falar de alguma pessoa que fez algo muito ruim, como um estuprador, um assassino. Neste caso, a esquerda estaria sendo equiparada a sujeitos que fazem mal a outras pessoas.

Quanto ao termo esquerdelhice, junto ressoa canalhice, esta ressonância traz imbuído uma má conduta dos sujeitos de esquerda, já que um sujeito canalha, conforme o dicionário Michaelis (2017), é alguém vil, ordinário e desprezível. Ou seja, o sujeito de esquerda é mau caráter e, mais uma vez, não é confiável. No exemplo a seguir isso fica bem claro:

Sou pior q cão farejador de esquerdelhice! kkkk olho tudo, vejo tudo.

Nesse exemplo já percebemos o tom de desconfiança, já que o sujeito diz estar sempre em busca de algo, muito por conta de que as pessoas de esquerda não podem ser confiáveis.

Outro sentido muito associado ao termo esquerda é o próprio Partido dos Trabalhadores (PT), percebemos nos comentários que ao falar de esquerda, a sua grande maioria, está se referindo ao PT, como se o único partido de esquerda fosse o PT. Isso fica claro nos seguintes exemplos:

Considero inadmissível, completamente inaceitável, a adesão de algumas escolas particulares à "greve" petista de 28/04. É preciso haver reação dos pais e pressão junto às diretorias ou conselhos das escolas. Não podemos aceitar pagar o salário de doutrinadores esquerdistas em escolas privadas.

Tem que demitir esse professor. Ele quer greve pra poder ficar atoa. É isso que ele pretende. Como todo petista.

Ambos os exemplos trazem o professor que adere a greve, mas não é qualquer professor, é o professor esquerdista e do PT, já que a greve é desse partido e é o que ele gosta 
de fazer, sendo os professores a favor dela, são, também de esquerda e, por consequência do PT.

O que percebemos a partir dessa análise é que o termo esquerda está sempre associado a algo negativo e os sujeitos esquerdistas não são confiáveis, ou porque são maus caráteres ou porque possuem algum tipo de doença ou distúrbio mental. Só isso explicaria a militância na esquerda. Salientamos, novamente, que está é apenas uma interpretação dentre tantas outras possíveis.

\section{Considerações finais}

Muitos outros sentidos ainda poderiam depreender, a partir da análise do termo esquerda, nos comentários na página oficial no Facebook do movimento Escola sem Partido, todos eles, pelo que vimos na análise, sempre imbuídos de negatividade e associados a algo ruim. Ou melhor dizendo, o Partido dos Trabalhadores (PT) é associado a uma ideologia negativa, onde os seus militantes têm um sério problema de caráter ou mental. Qualquer elemento que seja associado a esse partido, conforme nos apontam Venturini e Scherer (2017), serão considerados a causa e um modo de fazer o mal. Por isso que, nesse ambiente, os discursos sobre a esquerda, são sempre negativos porque estão vinculados ao PT.

Como vimos, ao enunciar esquerda, junto ressoa comunismo e todos os sentidos que a ele se inscrevem. Dessa forma, os sujeitos que enunciam tais discursos estão na ordem da repetibilidade, já que, conforme nos mostra Freda Indursky (2013), os sentidos imbricados ao comunismo soam há muito tempo. Esses sujeitos, então, se inscrevem em uma determinada FD, neste caso, a FD do comunismo negativo, e reduplicam em seus discursos, o discurso de imposição do comunismo. O que implica em um assujeitamento do sujeito à FD do comunismo como algo negativo. Ou ainda, conforme já citado neste trabalho, os sujeitos enunciantes por serem do meio digital, são afetados por instituições que funcionam como uma "máquina ideológica", aqui posta como o movimento ESP, por isso, os dizeres desse movimento estão sempre sendo repetidos, e, por isso, a esquerda continua sendo associada ao comunismo negativo.

Dessa forma, percebemos que todos os discursos negativos associados ao termo esquerda, se levarmos em conta o que Mariani (1998) nos coloca, são na verdade discursos ligados a FD do comunismo, que ressoa já a muito tempo, como vimos, antes mesmo de chegar ao Brasil. Já que esquerda e comunismo estão atrelados um ao outro. Essa forma negativa de se ver o comunismo, a esquerda, seria, então, uma forma de controle sobre o que Bethania Mariani (ibidem) chama de inimigo, já que no imaginário social, previamente 
estabelecido pela máquina ideológica, os comunistas, os esquerditas, são inimigos indesejáveis. Ou seja, os professores, agora são os inimigos, já que são eles que estão doutrinando.

Assim, também, a vinculação dos partidos de esquerda, ou melhor dizendo ao PT, a discursos negativos seria uma forma de reprimir o partido político, isso porque "[...] a repressão político-partidária se realiza concomitantemente à sua determinação negativa no plano da linguagem jornalística." (MARIANI, 1998, 123). De certa forma pelo medo que as elites têm da esquerda e do comunismo (VENTURINI e SCHERER, 2017). Daí que esses sentidos pensados a partir do acontecimento digital, em que o movimento ESP funcionando como "máquina ideológica", está afetando uma gama de sujeitos que acabam por repetir, atualizar e reatualizar (conforme DIAS) o discurso negativo atrelado aos professores de esquerda, aos professores do PT.

\section{Referências}

DIAS, C. A análise do discurso digital: um campo de questões. Revista Eletrônica de Estudos do Discurso e do Corpo - REDISCO, Vitória da Conquista, v. 10, n. 2, p.8-20, jul./dez. 2016. Disponível em: <http://periodicos.uesb.br/index.php/redisco/article/viewFile/6139/5880>. Acesso em: 20 maio. 2017.

INDURSKY, F. O trabalho discursivo do sujeito entre o memorável e a deriva. Signo y Seña - Revista del Instituto de Linguística, v. 24, p. 91-104, dez. 2013. Disponível em: <http://revistas.filo.uba.ar/index.php/sys/article/view/118>. Acesso em: 28 jun. 2017.

. Lula lá: estrutura e acontecimento. Organon - Revista do Instituto de Letras da URGS, v. 17, n. 35, p. 101-21, 2003. Disponível em: <http://seer.ufrgs.br/index.php/organon/issue/view/1706/showToc>. Acesso em: 27 jun. 2017.

MARIANI, Bethania. O PCB e a imprensa: os comunistas no imaginário dos jornais (1922-1989). Rio de Janeiro: Revan; Campinas: UNICAMP, 1998.

MICHAELIS. Dicionário Brasileiro da Língua Portuguesa. Disponível em: <http://michaelis.uol.com.br/>. Acesso em: 30 jun. 2017.

MOVIMENTO - Revista de Educação. Entrevista com Fernando Penna. Movimentos: Revista de Educação, Niterói, ano 2, n 3, p. 294-301, 2015. Disponível em: <http://www.revistamovimento.uff.br/index.php/revistamovimento/article/view/275/23 6>. Acesso em: 20 de jun. 2017. 
ORLANDI, P. E. Análise de Discurso. In: ORLANDI, P. E.; LAGAZZI-RODRIGUES, S. (Orgs). Discurso e textualidade. Campinas: Pontes, 2006. p. 11-31.

Interpretação: autoria, leitura e efeitos do trabalho simbólico. ed. 3. Petrópolis:

Vozes, 1996.

PÊCHEUX, M. Semântica e discurso: uma crítica à afirmação do óbvio. Tradução de Orlandi, et al. 3. ed. Campinas: Unicamp, 1997.

RODRIGUES, H. E. Escola sem Partido: a escola do nosso tempo? Disponível em: $<$ http://site.anpuh.org/index.php/2015-01-20-00-01-55/noticias2 /diversas/item/3594-escolasem-partido-a-escola-do-nosso-tempo>. Acesso em: 21 out. 2016.

VENTURINI, M. C.; SCHERER, A. E. O discurso do/sobre o ódio no contexto brasileiro: nosso compromisso político com o dizer. Fragmentum, Santa Maria, n. 50, jul./dez., 2017. p. 163-178. Disponível em: 〈https://periodicos.ufsm.br/fragmentum/article/view/31541/pdf〉. Acesso em: 17 abr. 2018. 